Revista Estudios, (41), 2020.

ISSN 1659-3316

Diciembre 2020-Mayo 2021

González Coto Marcela

Sáenz Cubillo Nayuribe

Dossier: V Simposio Internacional y IX Nacional sobre Derechos de la Niñez y la Adolescencia

\title{
Crianza Respetuosa: Hacia una parentalidad centrada en las niñas y los niños
}

\author{
Marcela González Coto \\ Fundación Paniamor, Costa Rica \\ marcelagonzalez@paniamor.org \\ https://orcid.org/0000-0001-7106-1140
}

Nayuribe Sáenz Cubillo
Fundación Paniamor, Costa Rica
primerainfancia@paniamor.org
https://orcid.org/0000-0003-4835-6172

Recibido: 1 de julio de 2020

Aceptado: 31 de setiembre de 2020

Resumen: Esta ponencia es una invitación a hacer un análisis crítico desde el Modelo Somos Familia de la Fundación Paniamor, para promover el imperativo de una crianza centrada en las necesidades, deseos y capacidades de las niñas y los niños. Desde esta intención se suman las ideas y principios del enfoque de derechos de las niñas y los niños, paradigma de la nueva niñez y crianza respetuosa, como respaldo que reafirma que el vínculo seguro y una crianza empática son el fundamento de una agencia ciudadana desde la primera infancia. Comprendiendo a la vez, que la eliminación del castigo físico y trato humillante es solo uno de los pasos para practicar una crianza respetuosa, ya que además se requiere la participación real de las niñas y los niños.

Palabras clave. Crianza respetuosa, derechos de las niñas y los niños, paradigma de la nueva niñez, crianza centrada en las niñas y los niños, primera infancia.

\section{Respectful Parenting: Towards a children-center parenting}$$
\text { (c) (i) (2)(2) }
$$

La Revista Estudios es editada por la Universidad de Costa Rica y se distribuye bajo una Licencia Creative Commons Atribución-NoComercial-CompartirIgual 3.0 Costa Rica. Para más información envíe un mensaje a revistaestudios.eeg@ucr.ac.cr.
} 
ISSN 1659-3316

Diciembre 2020-Mayo 2021

Dossier: V Simposio Internacional y IX Nacional sobre Derechos de la Niñez y la Adolescencia

Abstract: This lecture is an invitation to do a critical analysis based on the Somos Familia Model from Fundación Paniamor, in order to promote a parenting approach centered in children's needs, desires and capacities. In line with this objective, the ideas and principles of the children's rights approach, the new childhood paradigm and the respectful parenting approach are added, supporting that the secure attachment and empathetic parenting are the foundations to develop a civic agency from early childhood. Simultaneously, this analysis reinforces that removing physical punishment and humiliating treatment are only one step towards respectful parenting, since it also requires the real participation of children.

Keywords. Respectful parenting; children's rights; new childhood paradigm; children-center parenting; early childhood

La Revista Estudios es editada por la Universidad de Costa Rica y se distribuye bajo una Licencia Creative Commons Atribución-NoComercial-CompartirIgual 3.0 Costa Rica. Para más información envíe un mensaje a 
Dossier: V Simposio Internacional y IX Nacional sobre Derechos de la Niñez y la Adolescencia

\section{Introducción}

Fundación PANIAMOR trabaja en incorporar la cultura de los derechos de la niñez y la adolescencia en la acción política y social de Costa Rica y la región, para lo cual construye alianzas visionarias con el Estado y el sector privado. Así, desde su misión, busca empoderar a niñas, niños, adolescentes y sus familias para que construyan vidas amparadas en sus derechos. En este camino sostenido desde hace 32 años, PANIAMOR y sus aliados desarrollan y transfieren al Estado modelos relevantes, efectivos, sustentados en evidencia científica. De esta manera, se propone un escalamiento vía políticas y programas que contribuyen al desarrollo de la capacidad-país para afrontar la agresión y rechazo que algunas veces viven las personas menores de edad.

Bajo esta ruta, PANIAMOR tiene como objetivo que niñas y niños vivan plenamente su derecho a crecer sin violencia -incluidos el castigo físico y trato humillante-. Por eso, posiciona el enfoque de "crianza respetuosa" como su marco teóricometodológico para acompañar a las familias a desarrollar competencias parentales democráticas. Este enfoque toma fuerza al nutrirse de otros paradigmas como el de la "nueva niñez" y enfoques como "derechos y responsabilidades", "igualdad de género", "neuropsicológico" y "presencia plena". Desde este escenario se pretende evidenciar las fortalezas del enfoque de "crianza respetuosa" para el trabajo directo con las familias y cómo este cobra nuevos significados y referentes cuando está centrado en las niñas y los niños.

\section{Enmarcando la crianza respetuosa}

Este enfoque parte de la disciplina positiva, uno de los principales modelos sobre la crianza, que se centra en la práctica consistente de actitudes constructivas mediante las cuales las personas cuidadoras promueven el aprendizaje de habilidades para 
Dossier: V Simposio Internacional y IX Nacional sobre Derechos de la Niñez y la Adolescencia

la vida en las niñas y los niños. La persona cuidadora recurre a la comprensión, la reflexión y la inducción empática como herramientas claras para dejar atrás el foco de control externo del comportamiento de la niña y el niño, caracterizado por el castigo, la amenaza, el miedo o la vergüenza. Según Durrant (2016) este modelo de crianza, posee las siguientes dimensiones:

(a) Identificar y mantener siempre presentes los objetivos/metas de la crianza. Se les recomienda a las personas cuidadoras que al interactuar con las niñas y los niños, sobre todo en situaciones que implique estrés interpersonal, mantengan presente qué es lo que quieren obtener como resultado final de la crianza. Y, así, conservar la consistencia entre sus metas y sus prácticas de crianza.

(b) Proporcionar calidez afectiva y soporte que le brinden a las personas menores de edad seguridad emocional y perspectiva para orientarse. Aquí, se les instruye a las personas cuidadoras para que verbalicen con las niñas y los niños la razón de ser de las actitudes y conductas parentales y que las acompañen de calidez emocional. En ese grado, el contenido cognitivo de sus actuaciones estaría en consonancia con el tono emocional de la relación con la niña y el niño.

(c) Comprender a la niñez desde sus pensamientos y sentimientos respecto a sus situaciones y conductas en cada etapa de su desarrollo y según sus condiciones particulares. En este punto, este paradigma insiste en que las personas cuidadoras tengan presente que su manera de comprender las situaciones de crianza y la propia conducta de las personas menores de edad obedece a una perspectiva adulta. Mientras que la niña y el niño tienen una comprensión propia, que no es inferior o equivocada, sino diferente a la de la persona adulta.

\section{(C) $(\Theta \odot$}

La Revista Estudios es editada por la Universidad de Costa Rica y se distribuye bajo una Licencia Creative Commons Atribución-NoComercial-CompartirIgual 3.0 Costa Rica. Para más información envíe un mensaje a 
Dossier: V Simposio Internacional y IX Nacional sobre Derechos de la Niñez y la Adolescencia

(d) Concentrarse en la solución de los problemas, las situaciones de conflicto, acortar su duración y asegurar el aprendizaje de ambas partes. El modelo pone en primer plano las actitudes parentales que contribuyen a una crianza fluida, que evita el estancamiento y el desgaste del rol parental, lo que resulta de las actitudes evasivas, de la confrontación cíclica o de la competencia por el control conductual.

\subsection{Crianza respetuosa en el Modelo Somos Familia}

Fundación Paniamor genera una propuesta crítica del enfoque de crianza antes descrito a través de su Modelo de Formación en Competencias Parentales Somos Familia ${ }^{1}$. Se propone visibilizar el conflicto, el desafío y el cambio como experiencias ineludibles en las relaciones familiares y señala que, lo que hace la diferencia para una parentalidad democrática, es el tipo de actitudes y comportamientos mediante los que se afrontan estas circunstancias. Es decir, plantea que se logra una parentalidad democrática y respetuosa, cuando las personas cuidadoras adoptan actitudes y comportamientos que aporten al cumplimiento de los derechos y a la seguridad física y emocional de la niñez, incluso ante situaciones de conflicto, desafío o cambio (Baker-Henningham y Lopez, 2010; Cummings y Schatz, 2012; Harris-VanKeuren y Rodríguez, 2013; Fundación Paniamor, 2016; Pérez López, 2009; Phillips y Lowenstein, 2011).

En este sentido, se invita a las personas en roles de cuido de niñas y niños a participar en procesos de enriquecimiento y formación en competencias parentales. Estas últimas equivalen al conjunto de habilidades, destrezas y valores que requieren las personas cuidadoras para realizar las tareas de cuido y crianza, colocando como prioridad el bienestar y desarrollo de las personas menores de

\section{(C) $(\Theta \odot$}

La Revista Estudios es editada por la Universidad de Costa Rica y se distribuye bajo una Licencia Creative Commons Atribución-NoComercial-CompartirIgual 3.0 Costa Rica. Para más información envíe un mensaje a 
ISSN 1659-3316 González Coto Marcela Sáenz Cubillo Nayuribe

Dossier: V Simposio Internacional y IX Nacional sobre Derechos de la Niñez y la Adolescencia

edad; de forma tal que crezcan con capacidad empática, autorregulación y participación social.

La experiencia acumulada a partir del modelo permite acuñar crianza respetuosa como un estilo de cuido y educación sensible basado en el respeto, la disponibilidad, la calidez afectiva, el contacto físico constante e incondicional, la comunicación empática, la comprensión hacia la niña y el niño y la protección de sus derechos. Lo anterior implica un des-aprendizaje de antiguos conceptos y patrones basados en el autoritarismo y la violencia, para luego hacer uso consciente de nuevas y respetuosas formas de abordar los conflictos y retos en la crianza (Gonzalo, 2010; Fundación Paniamor, 2016).

Mediante esta definición se reafirma una potente idea, expresada como: la calidad del vínculo afectivo que se establece entre las figuras cuidadoras y las niñas y los niños, desde su nacimiento, es decisiva y su impacto se puede observar en numerosas áreas y funciones como la regulación y estabilidad emocional, autoconcepto, la calidad de su aprendizaje y de las relaciones que se establezcan con otras personas. De ahí la importancia de enfatizar que la construcción de vínculos afectivos seguros y respetuosos constituyen en un factor de protección, al reducir el riesgo de efectos negativos en el desarrollo durante el resto de la niñez y potenciar su agencia para una vida autónoma, productiva y satisfactoria (Majluf, 2012; Olds, 2006; Páez, 2007; Fundación Paniamor, 2016; Oates, Karmiloff-Smith y Johnson, 2012).

Ahora bien, la posibilidad de que las niñas y los niños desarrollen vínculos afectivos seguros se relaciona con el respeto, el afecto y la empatía con la que se construya esta relación, como se detalla a continuación:

\section{(C) $(00$}

La Revista Estudios es editada por la Universidad de Costa Rica y se distribuye bajo una Licencia Creative Commons Atribución-NoComercial-CompartirIgual 3.0 Costa Rica. Para más información envíe un mensaje a 
Dossier: V Simposio Internacional y IX Nacional sobre Derechos de la Niñez y la Adolescencia

(a) La persona cuidadora les respeta como personas únicas, por lo que reconoce el valor de sus aportes, comprende que su perspectiva de mundo es diferente y no por eso errónea, además les reta de acuerdo con su etapa de desarrollo y condiciones particulares. Este tipo de acercamiento posibilita que las niñas y los niños se reconozcan a sí mismos como personas y desarrollen un sentido de pertenencia en los entornos en que se desenvuelven (Fundación Paniamor, 2016; Meadows, 2010).

(b) Los vínculos cercanos de los que disponen las personas menores de edad se desarrollan con seguridad afectiva, por lo que crecen con la confianza de contar con figuras de referencia cuando experimentan alguna tensión o dificultad. En este caso, las personas cuidadoras son capaces de calmarles, apoyarles 0 contenerles y no se convierten en fuentes adicionales de estrés. Esta experiencia es fundamental, ya que la niña y el niño retornarán a esas experiencias internas reaseguradoras cuando enfrenten retos y desafíos en nuevos ambientes (Bertancourt y Andrade, 2007; Richaud de Minzi, 2006).

(c) La persona cuidadora realiza un acompañamiento con funcionamiento reflexivo, esto significa que puede comprender y, por consiguiente, empatizar con la experiencia interna (pensamientos y sentimientos) de la niña o el niño teniendo "en mente la mente del niño". Por lo que en esta reacción no hay juicios, etiquetas o estereotipos que definen porqué se presenta o está ausente cierta conducta.

De esta manera, se parte de que el desarrollo emocional, social y, por ende neurológico desde la primera infancia dependen, en gran medida, de la calidad del vínculo afectivo que se gesta con las personas cuidadoras. En este sentido, una niña o un niño que se siente querido, cuidado, protegido y valorado tendrá un vínculo afectivo constructivo y afianzará una pertenencia segura con las personas adultas significativas. Comprendiendo además que, una pertenencia segura implica que las personas menores de edad cuenten con un espacio en el que encuentren la

La Revista Estudios es editada por la Universidad de Costa Rica y se distribuye bajo una Licencia Creative Commons Atribución-NoComercial-CompartirIgual 3.0 Costa Rica. Para más información envíe un mensaje a 
Dossier: V Simposio Internacional y IX Nacional sobre Derechos de la Niñez y la Adolescencia protección de sus derechos y la satisfacción de sus necesidades biológicas y emocionales, lo que les permite afianzar su autonomía ${ }^{2}$ y de esta manera explorar y aprender del mundo que les rodea (Aguilera, 2007; Florez, 2011; Lane, Wellman, Olson, LaBounty, \& Kerr, 2010; Spritz, Sandberg, Maher, \& Zajdel, 2010; Velásquez, Barrera, \& Bukowski, 2006).

\section{II. ¿Por qué una crianza respetuosa centrada en las niñas y los niños?}

Para PANIAMOR, los elementos que caracterizan una crianza respetuosa se definen desde un posicionamiento ético, pues este tipo de crianza requiere estar centrada en la niñez y fundamentada por el enfoque de "derechos de las niñas y los niños" y en integración con el paradigma de la "nueva niñez", cuya sintonía reafirma que no puede haber crianza respetuosa sin reconocer a las personas menores de edad como sujetos de derecho. De ahí que el Modelo Somos Familia, se posiciona como un programa de formación de competencias parentales centrado en las niñas y los niños, distanciándose de una crianza que prioriza las demandas en función del buen comportamiento o acatamiento de las normas desde lógicas adultas.

Con la intención clara de particularizar cuándo estamos ante una propuesta de crianza respetuosa centrada en las niñas y los niños, a continuación se retoman los dos enfoques que cimientan estas bases:

\subsection{Crianza respetuosa desde el enfoque de derechos de las niñas y los niños}

Este enfoque asume que los derechos de las niñas y los niños, son el principal elemento de referencia para las políticas relacionadas con la niñez, pues les reconocen como actores sociales y además identifica a las personas cuidadoras, docentes, comunidades y gobiernos como responsables de brindarles respeto, cuidado, educación y servicios integrales en su propio interés superior (Fundación

\section{(C) $(0 \bigcirc$}

La Revista Estudios es editada por la Universidad de Costa Rica y se distribuye bajo una Licencia Creative Commons Atribución-NoComercial-CompartirIgual 3.0 Costa Rica. Para más información envíe un mensaje a 
Dossier: V Simposio Internacional y IX Nacional sobre Derechos de la Niñez y la Adolescencia

Paniamor, 2016; Woodrow \& Press, 2007). Sin embargo, es claro que se requiere, para el cumplimiento de estas políticas, una transformación radical en las actitudes de la opinión pública y actores sociales con presencia en el espacio público y privado (Woodhead y Oates, 2010).

Reconociendo el imperativo ético de partir del enfoque de "derechos de las niñas y los niños" en la crianza, se plantean las siguientes ideas (Fundación Paniamor, 2016):

(a) Se visibiliza el sentido de pertenencia como un derecho y necesidad básica. La niñez tiene derecho a crecer en ambientes donde sean alimentados, cuidados, aceptados y tratados con respeto. El sentido de pertenencia les posibilita reconocerse como parte de un grupo (familia, centro educativo o comunidad) y comprender que son seres importantes y que sus aportes son vitales para su entorno. Esto a la vez potencia el desarrollo de su identidad como sujetos con agencia y capacidad de influencia.

(b) La familia se reconoce como el espacio por excelencia para crecer y desarrollarse, de ahí la responsabilidad de las personas encargadas de proveer el sustento material, emocional y social que las niñas y los niños requieren, o en su defecto, la necesidad de la intervención del Estado (artículos 5, 7, 18, 27) ${ }^{3}$.

A partir de estas ideas e implicaciones (Ver Tabla $\mathrm{N}^{\circ} 1$ ), una crianza centrada en las niñas y los niños parte en primer lugar de su reconocimiento ciudadano, como personas completas y competentes en el presente. De ahí, que la negociación, la comprensión mutua, la definición conjunta de acuerdos y la escucha empática son sin lugar a duda, algunas de las herramientas que brinda la crianza respetuosa. En contraposición, la definición de límites desde la visión adulta, la imposición de reglas que fluctúan en el día a día, la creencia de que las personas menores de edad son

\section{(c) (i) (2)}

La Revista Estudios es editada por la Universidad de Costa Rica y se distribuye bajo una Licencia Creative Commons Atribución-NoComercial-CompartirIgual 3.0 Costa Rica. Para más información envíe un mensaje a 

irracionales, egocéntricas o que no les gusta asumir responsabilidades, quedan vedadas.

Tabla $N^{\circ} 1$. Implicaciones del enfoque de derechos de las niñas y los niños

\begin{tabular}{|c|c|c|}
\hline s y & & IS \\
\hline $\begin{array}{l}\text {-La niña y el niño son } \\
\text { reconocidos como personas } \\
\text { titulares de derechos y } \\
\text { respetados en su } \\
\text { individualidad en todos los } \\
\text { momentos de su desarrollo, es } \\
\text { decir, como iguales. } \\
\text {-Las personas menores de } \\
\text { edad contarán con las } \\
\text { condiciones yociales, } \\
\text { materiales y afectivas } \\
\text { necesarias. Serán orientadas } \\
\text { por su familia y comunidad } \\
\text { para su desarrollo óptimo } \\
\text { como ciudadanas } \\
\text { ciudadanos. y } \\
\text {-El Estado y todas las } \\
\text { instituciones sociales con roles } \\
\text { de guarda, crianza o tutela, } \\
\text { incluyendo la familia, se } \\
\text { comprometen a ejercer su rol } \\
\text { garante del debido } \\
\text { cumplimiento de los derechos } \\
\text { de las niñas y los niños. }\end{array}$ & $\begin{array}{l}\text { Deberes hacia las familias } \\
\text { participantes en el modelo: } \\
\text {-Reconocer y respetar a las familias } \\
\text { como primer espacio de construcción y } \\
\text { ejercicio de la ciudadanía. } \\
\text {-Priorizar el acompañamiento a las } \\
\text { familias en su agenda política e } \\
\text { institucional. } \\
\text {-Catalizar las competencias parentales } \\
\text { coherentes con el paradigma de la } \\
\text { "nueva niñez". } \\
\text {-Diseñar y aplicar los componentes y } \\
\text { actividades de Somos Familia como un } \\
\text { medio donde las familias ejecuten lo } \\
\text { siguiente: } \\
\text {-Reconocen la particularidad de los } \\
\text { derechos de la niñez. } \\
\text {-Son conscientes de de sus } \\
\text { características de desarrollo y } \\
\text { condiciones particulares. } \\
\text {-Se reconocen como garantes de los } \\
\text { derechos de la niña y el niño, } \\
\text { priorizando su bienestar y desarrollo. } \\
\text {-Protegen y fortalecen a las personas } \\
\text { menores de edad como iguales, para } \\
\text { prevenir y/o denunciar toda forma de } \\
\text { violencia. }\end{array}$ & $\begin{array}{l}\text {-Visualizar a la niñez como } \\
\text { agentes competentes y } \\
\text { protagonistas de su propio } \\
\text { desarrollo. } \\
\text {-Dispensar los medios sociales y } \\
\text { políticos por los cuales las } \\
\text { personas menores de edad se } \\
\text { expresan, representan, } \\
\text { construyen y desenvuelven como } \\
\text { sujetos sociales, mediante el } \\
\text { ejercicio de derechos, de sus } \\
\text { características singulares y sus } \\
\text { condiciones distintivas. } \\
\text {-Diseñar y aplicar los } \\
\text { componentes y actividades de } \\
\text { Somos Familia como un medio } \\
\text { donde las niñas y los niños: } \\
\text {-Aprenden a respetarse y a } \\
\text { respetar a las personas con } \\
\text { quienes se relacionan. } \\
\text {-Se reconocen como personas } \\
\text { valiosas e importantes. } \\
\text {-Sean acompañadas y } \\
\text { estimuladas a retarse y } \\
\text { reconocer sus condiciones y/o } \\
\text { limitaciones. } \\
\text {-Actúan con seguridad y buscan } \\
\text { fortalecer sus capacidades. }\end{array}$ \\
\hline
\end{tabular}

Fuente: Fundación Paniamor (2016)

La Revista Estudios es editada por la Universidad de Costa Rica y se distribuye bajo una Licencia Creative Commons Atribución-NoComercial-CompartirIgual 3.0 Costa Rica. Para más información envíe un mensaje a 
Dossier: V Simposio Internacional y IX Nacional sobre Derechos de la Niñez y la Adolescencia

El Enfoque de "derechos de las niñas y los niños" encuentra una sinergia fundamental con el enfoque de la "nueva niñez" que a continuación se detalla.

\subsection{Crianza respetuosa desde el paradigma de la nueva niñez}

Este paradigma deriva de la convergencia entre el enfoque del "desarrollo humano" con el de los "derechos humanos", para plantear un nuevo concepto de niñez en el que se reconoce la condición ciudadana de las niñas y los niños desde su nacimiento. La nueva niñez asume que las personas menores de edad son seres humanos completos, plenos de agencia e integridad, lo que les permite tomar decisiones según su etapa de desarrollo y condiciones particulares (Jones, 2009). Desde el día uno de su nacimiento, inician un proceso de exploración, apropiación y creación de nuevos significados del mundo que les rodea, lo que progresivamente se traduce en identidad, participación y agencia (LeVine, 2008; Meadows, 2010; Meyer, 2010; Montgomery, 2009; Fundación Paniamor, 2016; UNICEF, 2017).

Este nuevo concepto de niñez defiende que, para que exista un ejercicio ciudadano real desde la primera infancia, se requiere como condiciones indispensables que crezcan en entornos libres de toda forma de violencia, discriminación y negligencia y a su vez que se garanticen sus derechos de supervivencia, protección y participación. Estos derechos les permiten a las niñas y los niños expresarse, deliberar y tomar decisiones, a la vez que reciben el reconocimiento y validación adulta de sus posicionamientos (Castrillón Pachón, 2009; Shanahan, 2007; UNICEF, 2018).

El paradigma de la "nueva niñez" nutre de forma especial el Modelo Somos Familia porque destaca ideas (Fundación Paniamor, 2012) e implicaciones (ver Tabla №2) que se describen a continuación.

\section{(c) (i) (2)}

La Revista Estudios es editada por la Universidad de Costa Rica y se distribuye bajo una Licencia Creative Commons Atribución-NoComercial-CompartirIgual 3.0 Costa Rica. Para más información envíe un mensaje a revistaestudios.eeg@ucr.ac.cr. 
ISSN 1659-3316

Dossier: V Simposio Internacional y IX Nacional sobre Derechos de la Niñez y la Adolescencia

(a) La vivencia ciudadana de la niña y el niño es válida por sí misma. Con ello, se propone que la adultez deje de ser la norma y que se reconozcan los aportes únicos que hacen las personas menores de edad a sus grupos sociales. Para lograr esto, requieren ser validadas por lo que son en el presente y no por lo que podrían llegar a ser cuando crezcan. El reconocimiento de los derechos de la niñez es un deber de las personas adultas, aquí y ahora; su postergación es una distorsión y negación de su ciudadanía.

(b) Se requiere una redistribución de las fuerzas de poder entre las personas adultas y las niñas y los niños. Para que se practique un ejercicio real de la ciudadanía desde la primera infancia. Por lo cual es necesario transformar la creencia histórica de que la autonomía y la participación infantil son espacios que las personas adultas ceden a la niñez como regalías, para reconocer que estos son derechos de los cuales las niñas y los niños son titulares.

\section{(c) (i) (9)}

La Revista Estudios es editada por la Universidad de Costa Rica y se distribuye bajo una Licencia Creative Commons Atribución-NoComercial-Compartirlgual 3.0 Costa Rica. Para más información envíe un mensaje a revistaestudios.eeg@ucr.ac.cr. 
Dossier: V Simposio Internacional y IX Nacional sobre Derechos de la Niñez y la Adolescencia

\section{Tabla №2. Implicaciones del paradigma de la nueva niñez}

\begin{tabular}{|c|c|c|}
\hline $\begin{array}{l}\text { Implicaciones hacia el Estado, } \\
\text { las instituciones y la cultura }\end{array}$ & $\begin{array}{c}\text { Implicaciones hacia las familias } \\
\text { y los centros educativos }\end{array}$ & $\begin{array}{c}\text { Implicaciones hacia las } \\
\text { niñas y los niños }\end{array}$ \\
\hline $\begin{array}{l}\text {-Se enfatizan, principalmente, } \\
\text { los derechos relativos a la } \\
\text { participación en la creación de } \\
\text { entornos y condiciones de vida, } \\
\text { que se hacen efectivos de forma } \\
\text { paralela a los derechos de } \\
\text { supervivencia, desarrollo y los } \\
\text { derechos de protección. } \\
\text {-Se reconoce el conocimiento y } \\
\text { significado que las niñas y los } \\
\text { niños le atribuyen a su mundo } \\
\text { como diferente, pero no como } \\
\text { inferior. } \\
\text {-Se concibe a las personas } \\
\text { menores de edad como agentes } \\
\text { de sus propias vidas en la toma } \\
\text { de decisiones ante las } \\
\text { situaciones cotidianas y políticas } \\
\text { que les competen. } \\
\text {-Se reconoce el valor de la } \\
\text { contribución que las niñas y los } \\
\text { niños, como iguales, le hacen a } \\
\text { su mundo social, por lo que su } \\
\text { ausencia es irremplazable. }\end{array}$ & $\begin{array}{l}\text { Las personas adultas se } \\
\text { relacionan con las niñas y los } \\
\text { niños y reconocen su condición } \\
\text { ciudadana: } \\
\text {-Propician espacios, medios y el } \\
\text { desarrollo de habilidades para la } \\
\text { libre expresión de las emociones, } \\
\text { necesidades y criterios de las } \\
\text { personas menores de edad, en un } \\
\text { marco libre de estereotipos, } \\
\text { violencia y discriminación. } \\
\text {-En el entorno familiar y de cuido } \\
\text { institucional, se favorece el diálogo, } \\
\text { la negociación de las decisiones y la } \\
\text { participación real de la niñez, como } \\
\text { iguales y sin discriminación } \\
\text {-Las personas adultas le preguntan } \\
\text { a las niñas y los niños los motivos } \\
\text { de sus actos y les invitan a opinar de } \\
\text { forma razonada y a generar } \\
\text { comprensiones compartidas, en } \\
\text { igualdad de oportunidades y } \\
\text { condiciones. } \\
\text {-Las personas adultas enfatizan, } \\
\text { como iguales, en la voz e ideas de } \\
\text { la niñez para, luego, incorporarlas y } \\
\text { negociar con la voz e ideas de otras } \\
\text { personas adultas. } \\
\text {-Las personas adultas promueven } \\
\text { que las niñas y los niños desarrollen } \\
\text { tareas y actividades por sí mismos, } \\
\text { que los consoliden y, a su vez, se } \\
\text { reconozcan en sus identidades } \\
\text { singulares. }\end{array}$ & $\begin{array}{l}\text { Las niñas y los niños que } \\
\text { participan en Somos Familia } \\
\text { lo hacen como ciudadanas y } \\
\text { ciudadanos, por lo que } \\
\text { realizan las siguientes } \\
\text { funciones: } \\
\text {-Comunican de manera verbal } \\
\text { y no verbal, sus necesidades y } \\
\text { elecciones a las personas a su } \\
\text { cargo en todo momento. } \\
\text {-Comprenden y asumen, en la } \\
\text { medida de sus condiciones, las } \\
\text { responsabilidades personales } \\
\text { y colectivas que se les } \\
\text { atribuyen. } \\
\text {-Demuestran actitudes de } \\
\text { comprensión, solidaridad y } \\
\text { cooperación con otras niñas, } \\
\text { niños y personas adultas } \\
\text { significativas. } \\
\text {-Progresivamente, pueden } \\
\text { comunicar asertivamente a sus } \\
\text { figuras de referencia cuando no } \\
\text { están de acuerdo con ellas y } \\
\text { ellos. }\end{array}$ \\
\hline
\end{tabular}

Fuente: Fundación Paniamor (2016).

\section{(®) $\odot \odot$}

La Revista Estudios es editada por la Universidad de Costa Rica y se distribuye bajo una Licencia Creative Commons Atribución-NoComercial-CompartirIgual 3.0 Costa Rica. Para más información envíe un mensaje a 
Dossier: V Simposio Internacional y IX Nacional sobre Derechos de la Niñez y la Adolescencia

A partir de este paradigma, la crianza respetuosa centrada en la niña y el niño les concibe como personas partícipes de su proceso de desarrollo. Para esto se les acompaña a reconocer su propia voz, reflexionar, conocer las causas, consecuencias de sus acciones y las de otras personas, entender esto les permitirá, progresivamente, adquirir herramientas para su autorregulación. De esta forma queda claro que, primero se requiere tener la confianza de ser una persona valiosa, reconocida, escuchada para luego ir autorregulando las acciones propias en un entorno social.

Bajo la intención de dejar claro que la crianza respetuosa centrada en las niñas y los niños requiere la integración de más enfoques, se han seleccionado los anteriormente mencionados por considerarse nucleares. Esta posición permite dejar de lado que el desarrollo de una crianza respetuosa está ligada solamente a rutinas o técnicas que se les entregan a las familias para que las apliquen. Como se ha venido trabajando a lo largo de esta ponencia, la crianza respetuosa requiere partir del principio ético de que las niñas y los niños son personas, por tanto, ningún tipo de violencia (castigo físico, aislamiento físico-emocional, humillación, entre otros) son parte de su proceso de disciplina, como tampoco lo son las técnicas conductuales dirigidas a lograr obediencia desde un foco de control externo. Así, con el objetivo de profundizar esta posición y a modo de cierre de este apartado, a continuación se describe el enfoque de "crianza respetuosa" desde el Modelo Somos Familia.

\subsection{Implicaciones de una crianza respetuosa centrada en la niña y el niño}

Como se ha mencionado, desde PANIAMOR se considera que la crianza respetuosa es un estilo de cuido en el que las personas adultas cuidadoras se esfuerzan por desarrollar competencias parentales que les permitan criar a las niñas y los niños, reconociendo como prioridad su bienestar y desarrollo. Esto se

La Revista Estudios es editada por la Universidad de Costa Rica y se distribuye bajo una Licencia Creative Commons Atribución-NoComercial-CompartirIgual 3.0 Costa Rica. Para más información envíe un mensaje a revistaestudios.eeg@ucr.ac.cr. 
ISSN 1659-3316

Dossier: V Simposio Internacional y IX Nacional sobre Derechos de la Niñez y la Adolescencia

enfatiza desde el vínculo, donde se reconoce a las personas menores de edad como seres humanos completos y se lucha por garantizar el cumplimiento de sus derechos.

El enfoque de crianza respetuosa advierte de la importancia que determina para el desarrollo de la persona y de sus relaciones sociales el contar, desde la primera infancia, con vínculos seguros y protectores. Su aporte respalda los esfuerzos actuales para formar a padres y madres, cuidadores y cuidadoras en general en las competencias que dan lugar a la vinculación fiable. Esto es la capacidad empática, la respuesta y acompañamiento frente al estrés emocional, la modelación de la auto-regulación, entre otros (ver Tabla №3) (Cole \& Packer, 2016; Gross, Stern, Brett, \& Cassidy, 2017; Fundación Paniamor, 2016; UNICEF, 2017).

\section{(c) (1) (2)}

La Revista Estudios es editada por la Universidad de Costa Rica y se distribuye bajo una Licencia Creative Commons Atribución-NoComercial-CompartirIgual 3.0 Costa Rica. Para más información envíe un mensaje a revistaestudios.eeg@ucr.ac.cr. 
Dossier: V Simposio Internacional y IX Nacional sobre Derechos de la Niñez y la Adolescencia

\section{Tabla N³. Implicaciones para la crianza respetuosa}

\begin{tabular}{|c|c|c|c|}
\hline $\begin{array}{l}\text { es hacia } \\
\text {, las } \\
\text { ies y la } \\
\text { ra }\end{array}$ & \multicolumn{2}{|c|}{$\begin{array}{l}\text { Implicaciones hacia las familias y los centros } \\
\text { educativos }\end{array}$} & \\
\hline $\begin{array}{l}\text {-La niña y el niño son } \\
\text { reconocidos en su } \\
\text { individualidad como } \\
\text { personas ras y } \\
\text { respetados según su } \\
\text { momento de vida. } \\
\text {-Las personas } \\
\text { menores de edad } \\
\text { son sustentadas y } \\
\text { orientadas en su } \\
\text { desarrollo óptimo } \\
\text { comor agentes } \\
\text { sociales. } \\
\text {-Se demanda a las } \\
\text { instituciones con } \\
\text { roles de guarda, } \\
\text { crianza o tutela, } \\
\text { principalmente la } \\
\text { familia y el Estado, el } \\
\text { debido cumplimiento } \\
\text { de sus roles como } \\
\text { garantes r del } \\
\text { cumplimiento de } \\
\text { estos derechos. }\end{array}$ & $\begin{array}{l}\text { El entorno familiar: } \\
\text {-Es reconocido como } \\
\text { un espacio seguro, en } \\
\text { el que se sienten parte } \\
\text { importante y por tanto } \\
\text { les gusta estar. } \\
\text {-Espacio socio-afectivo } \\
\text { que se caracteriza por } \\
\text { un ambiente cálido, } \\
\text { sensible y de escucha } \\
\text { ante las necesidades y } \\
\text { demandas de las niñas } \\
\text { y los niños. } \\
\text {-Reconocido como un } \\
\text { espacio protector } \\
\text { donde las personas } \\
\text { adultas se esfuerzan } \\
\text { reflexivamente por } \\
\text { cubrir todas sus } \\
\text { necesidades básicas y } \\
\text { afectivas. }\end{array}$ & $\begin{array}{l}\text {-Establecen con las } \\
\text { personas menores de } \\
\text { edad límites claros, firmes } \\
\text { y flexibles en ausencia de } \\
\text { violencia. } \\
\text {-Modelan a las niñas y los } \\
\text { niños un repertorio de } \\
\text { destrezas sociales } \\
\text { proactivas, asertivas y } \\
\text { altruistas. }\end{array}$ & $\begin{array}{l}\text { Las niñas y los niños } \\
\text { como personas amadas } \\
\text { y seguras: } \\
\text {-Identifican y expresan } \\
\text { sin temor sus } \\
\text { emociones. } \\
\text {-Progresivamente } \\
\text { resuelven con empatía } \\
\text { conflictos, retos o } \\
\text { situaciones que les } \\
\text { provocan emociones } \\
\text { intensas. las } \\
\text {-Identifican a } \\
\text { personas adultas con } \\
\text { quienes tienen vínculos } \\
\text { seguros y buscan su } \\
\text { apoyo. } \\
\text {-Muestran seguridad al } \\
\text { desarrollar actividades } \\
\text { por su cuenta. }\end{array}$ \\
\hline
\end{tabular}

Fuente: Fundación Paniamor (2016)

La Revista Estudios es editada por la Universidad de Costa Rica y se distribuye bajo una Licencia Creative Commons Atribución-NoComercial-CompartirIgual 3.0 Costa Rica. Para más información envíe un mensaje a 
Dossier: V Simposio Internacional y IX Nacional sobre Derechos de la Niñez y la Adolescencia

\section{Conclusiones}

En la actualidad existen múltiples modelos de crianza que se han nutrido de las investigaciones en desarrollo infantil de los últimos años. Desde PANIAMOR se ha optado por revisar constantemente esta literatura y analizarla junto con la experiencia de las familias, para así adoptar las ideas y prácticas que potencian un vínculo en el que se prioriza el bienestar y desarrollo de las niñas y los niños.

Ahora bien, es central reconocer que la fundamentación de programas o modelos de parentalidad desde el enfoque de "derechos de niñas y niños", paradigma de la "nueva niñez" y finalmente, su articulación en el enfoque de "crianza respetuosa", marca un antes y un después en la forma en que concebimos a las niñas, los niños y sus familias. $Y$ desde ahí, las estrategias para trabajar hacia rutas de cambio cultural, donde no solo se rechace el castigo físico, el trato humillante y la negligencia, sino que además se le dé un lugar a las niñas y a los niños como sujetos de derecho y se priorice la construcción de un vínculo afectivo respetuoso y seguro. Lo anterior implica que, además de eliminar formas violentas que se habían adoptado como métodos de crianza, se promueva la creación de espacios en los que se valoren los aportes de las niñas y los niños, se responda a sus necesidades con respeto y empatía, así como que se garantice el cumplimiento de sus derechos.

En esta línea, esta ponencia se considera un acercamiento para generar un análisis crítico sobre nuestros referentes éticos, teóricos y metodológicos para trabajar con las familias en pro de una crianza respetuosa. $Y$ reconocer que el cambio cultural hacia una crianza realmente respetuosa, requiere sin duda, dejar de formar, criar o aplicar disciplina para sintonizar con los mandatos, deberes o necesidades de las personas adultas y en su lugar, poner en el centro a las niñas y los niños.

\section{(ब) (ब๑)}

La Revista Estudios es editada por la Universidad de Costa Rica y se distribuye bajo una Licencia Creative Commons Atribución-NoComercial-CompartirIgual 3.0 Costa Rica. Para más información envíe un mensaje a 
Dossier: V Simposio Internacional y IX Nacional sobre Derechos de la Niñez y la Adolescencia

\section{Notas}

1. La construcción del Modelo Somos Familia inició en enero del año 2013, gracias a la alianza público privada establecida entre Procter \& Gamble, Alianza Empresarial para el Desarrollo y la Fundación PANIAMOR, junto con la Dirección Nacional de CENCINAI, adscrita al Ministerio de Salud. El Modelo Somos Familia se institucionalizó como el Programa de Formación Parental de la Dirección Nacional CENCINAI y se incluyó en su normativa interna para ser aplicado nacionalmente de forma sostenible con recursos estatales. Según el último registro aportado por la Dirección Nacional CEN-CINAI en el año 2018, las 7 Regiones están aplicando Somos Familia. Se registran 19423 de personas adultas participantes y 15281 personas menores de edad (7523 niños y 7758 niñas). Así mismo, en el 2018, Somos Familia obtuvo el premio "Responsabilidad Social en Acción", otorgado por la Cámara Costarricense Norteamericana de Comercio (AmCham), en la categoría Alianzas Público Privada.

2. La independencia y la autonomía son dimensiones y logros diferentes del desarrollo. La independencia corresponde a la adquisición de destrezas y hábitos sensorio-motores que le permiten a la niña y al niño realizar actividades cotidianas como mudarse, abrocharse la ropa, amarrar los zapatos, cepillarse los dientes, patinar, manejar bicicleta, entre otros. La autonomía se refiere a una esfera más integral, cognoscitiva y emocional, basada en el sentimiento de seguridad y asertividad, en áreas como las de los hábitos, pero, sobre todo, en el plano interpersonal y social. Las cuidadoras y cuidadores generalmente confunden los dos términos, lo cual crea una confusión en las metas de una crianza positiva, con secuelas negativas en el desarrollo infantil.

\section{(c) (i) (2)}

La Revista Estudios es editada por la Universidad de Costa Rica y se distribuye bajo una Licencia Creative Commons Atribución-NoComercial-CompartirIgual 3.0 Costa Rica. Para más información envíe un mensaje a 
ISSN 1659-3316

Dossier: V Simposio Internacional y IX Nacional sobre Derechos de la Niñez y la Adolescencia

\section{Según UNICEF (2006):}

Artículo 5: Es obligación del Estado respetar las responsabilidades y los derechos de los padres y madres, así como de otros familiares, de impartir al niño orientación apropiada para la evolución de sus capacidades.

Artículo 7: El niño será inscripto inmediatamente después de su nacimiento y tendrá derecho, desde que nace, a un nombre, a adquirir una nacionalidad y, en la medida de lo posible, a conocer a sus padres y a ser cuidado por ellos.

Artículo 18. Es responsabilidad primordial de padres y madres la crianza de los niños y es deber del Estado brindar la asistencia necesaria en el desempeño de sus funciones.

Artículo 27. Los Estados partes reconocen el derecho de todo niño a un nivel de vida adecuado para su desarrollo físico, mental, espiritual, moral y social.

\section{(c) (i) (9)}

La Revista Estudios es editada por la Universidad de Costa Rica y se distribuye bajo una Licencia Creative Commons Atribución-NoComercial-CompartirIgual 3.0 Costa Rica. Para más información envíe un mensaje a revistaestudios.eeg@ucr.ac.cr. 
Dossier: V Simposio Internacional y IX Nacional sobre Derechos de la Niñez y la Adolescencia

\section{Referencias bibliográficas}

Aguilera, M. I. (2007). Comprensión empática y estilos de negociación en la relación de pareja. Herramientas de mediación. Revista Interdisciplinaria de Resolución y Mediación de Conflictos, 23, 110-123. doi: 10.33670/18181023.v10i02.55

Baker-Henningham, H. \& Lopez, F. (2010). Early Childhood Stimulation Interventions in Developing Countries: A Comprehensive Literature Review. IZA Discussion Paper No. 5282. Recuperado de https://papers.ssrn.com/sol3/papers.cfm?abstract id=1700451

Bertancourt D. \& Andrade P. (2007). Escala de Percepción del Control Parental de Niños. Ciencias Sociales y Humanidades, 6, 26-34. Recuperado de dialnet.unirioja.es/descarga/articulo/2695339.pdf

Castrillón Pachón, X. (2009). ¿Dónde están los niños? Rastreando la mirada antropológica sobre la infancia. Maguaré, 23, 434-469. doi: $10.2307 / 25597211$

Cole, M., \& Packer, M. (2016). A Bio-Cultural-Historical Approach to the Study of Development. Handbook of Advances in Culture and Psychology, 6, 1-76. doi: 10.1093/acprof:oso/9780190458850.003.0001

Cummings, E.M. \& Schatz, J. (2012). Family Conflict, Emotional Security, and Child Development: Translating Research Findings into a Prevention Program for Community Families. Clinical, Children and Family Psychological Review, 15, 14-27. doi: 10.1007/s10567-012-0112-0

Durrant, J. (2016). Positive discipline in everyday parenting. Sweden: Save the Children.

Florez, I. R. (2011). Developing young children's self-regulation through everyday experiences. Young Children, 66(4), 46-54. Recuperado de http://search.ebscohost.com.ezproxy.sibdi.ucr.ac.cr:2048/login.aspx?direct=tr $\underline{\mathrm{ue} \& \mathrm{db}=\mathrm{ehh} \& \mathrm{AN}=64922618 \& \text { site }=\text { ehost-live } \& \text { scope }=\text { site }}$

\section{(C) $(00$}

La Revista Estudios es editada por la Universidad de Costa Rica y se distribuye bajo una Licencia Creative Commons Atribución-NoComercial-CompartirIgual 3.0 Costa Rica. Para más información envíe un mensaje a revistaestudios.eeg@ucr.ac.cr. 
Dossier: V Simposio Internacional y IX Nacional sobre Derechos de la Niñez y la Adolescencia

Fundación Paniamor. (2012). Modelo Niñez Ciudadana. Costa Rica: Fundación PANIAMOR.

Fundación Paniamor. (2016). Modelo de Formación Parental Somos Familia. Marco Referencial. Costa Rica: Fundación PANIAMOR.

Gonzalo, N. (2010). Educar en positivo. Revista Iberoamericana Sobre Calidad, Eficacia y Cambio En Educación, 8(2), 157-165. Recuperado de https://revistas.uam.es/index.php/reice/article/view/5365

Gross, J. T., Stern, J. A., Brett, B. E., \& Cassidy, J. (2017). The multifaceted nature of prosocial behavior in children: Links with attachment theory and research. Social Development, 26(4), 661-678. doi: 10.1111/sode.12242

Harris-VanKeuren, C., \& Rodríguez, D. (2013). Pautas para el aprendizaje temprano en América Latina y el Caribe. Recuperado de https://publications.iadb.org/es/pautas-para-el-aprendizaje-temprano-enamerica-latina-y-el-caribe

Jones, P. (2009). Rethinking Childhood. Attitudes in Contemporary Society. Gran Bretaña: Continuum International Publishing Group.

Lane, J. D., Wellman, H. M., Olson, S. L., LaBounty, J., \& Kerr, D. C. R. (2010). Theory of mind and emotion understanding predict moral development in early childhood. British Journal of Developmental Psychology, 28(4), 871889. doi: $10.1348 / 026151009 \times 483056$

LeVine, R. (2008). Anthropology and Child Development: A cross-cultural reader. Malden, MA: Blackwell Pub.

Majluf, A. (2012). Prácticas de crianza en madres de estratos socioeconómico medio y bajo de Lima. Revista de Psicología, 7(2), 151-161. Recuperado de http://revistas.pucp.edu.pe/index.php/psicologia/article/view/3749/3727

Meadows, S. (2010). The child as social person. Canadá: Routledge.

Meyer, J. W. (2010). World Society, Institutional Theories, and the Actor. Annual Review of Sociology, 36(1), 1-20. doi: 10.1146/annurev.soc.012809.102506

\section{(2) $(\triangle \Theta \odot$}

La Revista Estudios es editada por la Universidad de Costa Rica y se distribuye bajo una Licencia Creative Commons Atribución-NoComercial-CompartirIgual 3.0 Costa Rica. Para más información envíe un mensaje a revistaestudios.eeg@ucr.ac.cr. 
Dossier: V Simposio Internacional y IX Nacional sobre Derechos de la Niñez y la Adolescencia

Montgomery, H. (2009). An introduction to childhood. Anthropological perspectives on childrens lives. USA: Wiley-Blackwell.

Oates, J., Karmiloff-Smith, A., \& Johnson, M. (2012). La Primera Infancia en Perspectiva. El cerebro en desarrollo. Reino Unido: The Open University.

Olds, D. (2006). The Nurse-Family Partnership: An evidence-based preventive intervention. Infant Mental Health Journal, 27(1), 5-25. doi:

10.1002/imhj.20077

Páez, D. (2007). Apego seguro, vínculos parentales, clima familiar e inteligencia emocional. Ansiedad y Estrés, 12(2-3), 329-341. Recuperado de https://www2.uned.es/dpto-psicologia-social-yorganizaciones/paginas/profesores/Itziar/IE AEstres06.pdf

Pérez López, J. (2009). Atención temprana : nuevos retos en el siglo XXI. Revista Interuniversitaria de Formación de Profesorado, 65(23), 15-20. Recuperado de http://www.redalyc.org/articulo.oa?id=27419063001

Phillips, D. \& Lowenstein, A. (2011). Early Care, Education and Child Development. Annual Review Psychologhy, 62, 483-500. doi: 10.1146/annurev.psych.031809.130707

Richaud de Minzi, M. C. (2006). Loneliness and depression in middle and late childhood: the relationship to attachment and parental styles. The Journal of Genetic Psychology, 167(2), 189-210. doi: 10.3200/GNTP.167.2.189-210

Shanahan, S. (2007). Lost and Found: The Sociological Ambivalence Toward Childhood. Annual Review of Sociology, 33, 407-428. doi: 10.1146/annurev.soc.33.040406.131808

Spritz, B. L., Sandberg, E. H., Maher, E., \& Zajdel, R. T. (2010). Models of Emotion Skills and Social Competence in the Head Start Classroom. Early Education \& Development, 21(4), 495-516. doi: 10.1080/10409280902895097

UNICEF. (2006). Convención sobre los Derechos del Niño. Madrid. Recuperado de https://www.un.org/es/events/childrenday/pdf/derechos.pdf

\section{(c) (i) (9)}

La Revista Estudios es editada por la Universidad de Costa Rica y se distribuye bajo una Licencia Creative Commons Atribución-NoComercial-CompartirIgual 3.0 Costa Rica. Para más información envíe un mensaje a revistaestudios.eeg@ucr.ac.cr. 
Dossier: V Simposio Internacional y IX Nacional sobre Derechos de la Niñez y la Adolescencia

UNICEF. (2017). UNICEF-La primera infancia importa para cada niño.pdf. La primera infancia importa para cada niño (Fondo de I). New York. Recuperado de https://www.valenciaport.com/autoridad-portuaria/sobre-valencia-port/planestrategico/

UNICEF. (2018). Plan estratégico. Plan Estratégico de UNICEF. 2018-2021 (Fondo de I). New York. Recuperado de https://www.valenciaport.com/autoridad-portuaria/sobre-valencia-port/planestrategico/

Velásquez, A. M., Barrera, F., \& Bukowski, W. (2006). Crianza y comportamiento moral: un modelo mediacional. Suma Psicológica, 13(2), 141-158.

Recuperado de http://pepsic.bvsalud.org/scielo.php?pid=S0121$\underline{43812006000200004 \& \text { script=sci arttext\&tlng=en }}$

Woodhead, M. \& Oates, J. (2010). La Primera Infancia en Perspectiva 5. Apoyo a los padres. Reino Unido: The Open Univeresity. Recuperado de http://baseddp.mec.gub.uy/Documentos/Bibliodigi/Apoyo-a-los-padres.pdf

Woodrow, C., \& Press, F. (2007). (Re)Positioning the Child in the Policy/Politics of Early Childhood. Educational Philosophy and Theory, 39(3), 312-325. doi: 10.1111/j.1469-5812.2007.00328.x

La Revista Estudios es editada por la Universidad de Costa Rica y se distribuye bajo una Licencia Creative Commons Atribución-NoComercial-CompartirIgual 3.0 Costa Rica. Para más información envíe un mensaje a revistaestudios.eeg@ucr.ac.cr. 